\title{
A presença da Esso na imprensa brasileira
}

Marcio de Souza Castilho

\section{Resumo:}

O artigo tem o objetivo de identificar alguns fatores sócio-históricos que levaram a empresa Esso Standard do Brasil a aproximar-se do campo jornalístico na década de 1950. Dentre as estratégias podemos destacar a criação do Repórter Esso, no rádio e na televisão, o investimento da empresa em publicidade na imprensa escrita e a constituição do Prêmio Esso de Jornalismo, o mais importante programa de reconhecimento do trabalho de jornalistas no país. Nesse processo, não há como dissociar a atuação da multinacional dentro de uma dinâmica social e política mais ampla.

\section{Palavras Chave:}

identidade; imprensa; memória.

\section{Abstract:}

The article identifies some historical factors that led Esso Company to approach the journalistic community in the 1950's. We can highlight, among the company's strategies, the creation of Esso Reporter, on radio and television, the company's investment in advertising and the creation of the Esso Award, the most important award given to the Brazilian press. Thus, we can't ignore the performance of this multinational company on a wider social and political dynamic.

\section{Keywords:}

identity; press; memory.

\section{Introdução}

Autorizada a instalar-se no país por decreto do presidente Hermes da Fonseca em 17 de janeiro de 1912, a empresa «Standard Oil Company of Brazil» foi precursora na distribuição de produtos de petróleo, como a gasolina e o querosene. As primeiras bombas de combustíveis no Rio de Janeiro foram instaladas pela empresa, que também abasteceu as primeiras aeronaves da aviação comercial brasileira. O nome Esso era uma adaptação fonética proveniente das iniciais de «Standard Oil». Nelson Rockfeller era encarregado de defender os negócios da empresa na América Latina, para onde o grupo expandira-se, sobretudo, a partir do início do século XX. A empresa passou a ser denominada Esso Standard do Brasil a partir de $1^{\circ}$ de janeiro de 1953.

A Esso diversificou suas atividades para além do mercado de combustíveis e dirigiu seus esforços para o campo da comunicação a partir dos anos 1940. Três ações podem ser destacadas na aproximação da multinacional com a comunidade jornalística: a criação do Repórter Esso, posteriormente transmitido na televisão, o investimento publicitário em jornais e revistas, e a implantação, em 1956, do Prêmio Esso de Jornalismo.

\section{O Repórter Esso}

Uma das estratégias que as grandes empresas estrangeiras no país utilizavam para manter uma imagem 
institucional positiva junto ao público era vincular sua marca a um determinado programa radiofônico. Esse tipo de ação de marketing foi proposto por algumas das principais agências de publicidade americanas presentes no Brasil, dentre elas a «McCan Erickson»e a «J. Walter Thompson». Iniciativas pioneiras nesse sentido foram desencadeadas pela «Colgate-Palmolive Pest Co.», uma das maiores anunciantes no país. Um dos programas, veiculados pela Rádio Record, de São Paulo, chamava-se "Palmolive no palco", apresentado por Otávio Gabus Mendes e que tinha no elenco músicos e artistas conhecidos do público, como a cantora Izaurinha Garcia e o sambista Vassourinha. A «Colgate-Palmolive» também patrocinou a montagem de radionovelas (JUNG, 2005: 30).

Caminho semelhante seguiu o grupo Esso, comandado pela família Rockfeller. A Esso não atuou diretamente em programas de entretenimento, optando por dirigir seus investimentos no campo do jornalismo. A sugestão de criar um noticiário radiofônico partiu da agência de publicidade «McCann Erickson», responsável pela conta da empresa no Brasil. Assim, às 12h55 do dia 28 de agosto de 1941, entrava no ar pela Rádio Nacional, do Rio de Janeiro, a primeira edição do Repórter Esso. Em suas primeiras transmissões, o programa também era veiculado pela Rádio Record, de São Paulo. Ambas tinham forte aceitação popular, sendo duas das mais importantes emissoras do país no início dos anos 1940 (1).

Com alto índice de audiência, o Repórter Esso logo seria retransmitido por emissoras em todo o país, como a Rádio Inconfidência (MG), Rádio Farroupilha (RS) e Rádio Clube (PE). As edições diárias de cinco minutos entravam no ar pontualmente às $8 \mathrm{~h}, 12 \mathrm{~h} 55,19 \mathrm{~h} 55$ e $22 \mathrm{~h} 55$, mas o programa poderia interromper a programação normal em casos extraordinários. Principal noticiário radiofônico brasileiro, o programa teve Heron Domingues como apresentador a partir de 1944. Vencedor de um concurso nacional, o locutor era famoso por incorporar certa dramaticidade na leitura das notícias. Tinha também o hábito de calcular o tempo de leitura. De fato, o programa que fixava como marca "o primeiro a dar as últimas" privilegiava a síntese no noticiário. As notícias eram redigidas em períodos curtos e de forma direta. A regra básica era evitar, por exemplo, adjetivações no texto e o uso de orações intercaladas. O noticiário seguia um tipo de manual de redação, contendo três princípios fundamentais. Um dos produtores do programa Merival Júlio Lopes enumera essas regras: "O Repórter Esso é um programa informativo; o Repórter Esso não comenta as notícias; o Repórter Esso sempre fornece as fontes de notícias” (LOPES, apud MOREIRA, 1991: 26).

Tais diretrizes apontam para uma forte influência do jornalismo americano. Não apenas na forma. O conteúdo também tinha nítida carga ideológica. O bordão, consagrado por Heron Domingues, mostrava como o noticiário dependia dos boletins da «United Press International» (UPI): "Prezado ouvinte, bom dia. Aqui fala o Repórter Esso, testemunha ocular da história, apresentando as últimas notícias da UPI". Um prefixo musical de fanfarras e clarins, composto pelo maestro Carioca, anunciava o início do programa.

Era através deste noticiário que os ouvintes recebiam as informações sobre a Segunda Guerra Mundial. Como principal fonte de informação sobre o conflito, o Repórter Esso consolidou, de 1941 a 1945, a sua audiência. Mais do que isso, serviu como importante instrumento na chamada "política de boa vizinhança" implantada pelos Estados Unidos para estreitar suas relações políticas, econômicas e culturais com os países da América Latina. Importa lembrar que o Repórter Esso, seguindo o mesmo formato da edição brasileira, era retransmitido em 14 países da América do Sul e Central por 59 estações de rádio (KLÖCKNER, 2001). Como meio de comunicação de massa, o rádio foi um dos veículos mais utilizados durante a guerra para neutralizar a influência do nazismo na América Latina e no Brasil, onde se registrava forte presença de imigrantes alemães, italianos e japoneses.

Se nos primeiros anos de sua transmissão no Brasil, o Repórter Esso colocava-se a serviço da propaganda de guerra, o programa radiofônico aproveitou também a sua popularidade para divulgar para os brasileiros o estilo de vida americano da época. Integrava-se assim a outros veículos de comunicação, como as revistas «Seleções do Reader's Digest» e «Visão». Dirigidas por grupos estrangeiros, estas publicações circulavam no 
Brasil e estimulavam o «American Way of Life» no contexto de expansão do mercado internacional. Empresas como «RCA Victor»e «General Eletric» lançaram seus produtos no mercado brasileiro. O cinema também participou ativamente dessa política, sobretudo através dos filmes de Walt Disney, difundindo o modo de vida americano. O Repórter Esso manteve-se no ar até 31 de dezembro de 1968.

Com o advento da televisão no Brasil, em 1950, por iniciativa do proprietário dos Diários Associados Assis Chateaubriand (2), o programa originado no rádio também ganhou sua versão para a TV. O Repórter Esso estreou na TV Tupi de São Paulo, em 17 de junho de 1953, com apresentação de Kalil Filho. Um ano depois, o telejornal foi lançado na TV Tupi do Rio de Janeiro, tendo como apresentador Gontijo Teodoro. Os dois profissionais, conhecidos locutores de rádio, já começavam a adaptar o programa para uma linguagem mais televisiva. O texto era objetivo, refletindo a estrutura narrativa do telejornalismo produzido nos EUA, e o apresentador, enquadrado no plano americano (3) (PATERNOSTRO, 1999: 35). No seu formato original, o programa tinha duração de cinco minutos e era exibido várias vezes ao dia com as notícias mais recentes (TEODORO, apud SOUZA, 2004: 150). O famoso noticiário deixou de ser transmitido na TV em 1970, anos depois da sua extinção no rádio.

\section{A operação publicitária}

Os anos 1950 são vistos como momento fundador para a imprensa, com a incorporação de um conjunto de técnicas tanto administrativas como editoriais. Como consequiência, o mercado jornalístico, sobretudo no Rio de Janeiro, sofreu uma forte retração. Ao mesmo tempo, o país vivia um clima de intenso debate político sobre a questão do petróleo. A campanha em defesa da solução estatal do petróleo resultou, em 1953, na criação da Petrobras. Levar em conta esses dois fatores históricos - o processo de modernização da imprensa e a questão do petróleo na década de 50 - é fundamental, ao nosso ver, para compreender a forte penetração de recursos publicitários de empresas públicas e privadas em jornais e revistas.

O processo de concentração da imprensa acompanhou o mesmo ritmo do desenvolvimento dos jornais em empresas modernas. Vários fatores podem ser apontados como determinantes para a retração do mercado jornalístico, especialmente no Rio de Janeiro nos anos 1950: as limitações técnicas decorrentes da necessidade da implantação de equipamentos modernos e caros para sustentar grandes tiragens em curto prazo de tempo e os custos adicionais para qualificação da mão-de-obra num momento de profissionalização da imprensa. Podemos apontar também o equilíbrio econômico precário da maior parte das publicações. Muitas apresentavam ainda gestão ineficiente ou sofriam corte de verbas oficiais ou publicidade comercial por motivos políticos. Outras razões, externas ao campo, agravavam a saúde financeira das empresas, como as dificuldades de importação do papel de imprensa (4) e a vulnerabilidade da economia brasileira, ainda em vias de modernização nos anos 1950.

A complexidade das operações e a transformação dos jornais em grandes empresas demandavam grandes recursos. No Brasil, esse volume de capital ainda era escasso. Tal defasagem entre o tamanho que assumiam as empresas de comunicação e a fragilidade da economia local para sustentar o peso da modernização da imprensa provocou uma significativa redução do número de jornais e revistas em circulação. Esse processo foi acentuado com o golpe militar de 1964. É importante afirmar que a sobrevivência das empresas jornalísticas que atingiram certa estabilidade financeira não significou, em nenhum momento, sua autonomia em relação ao campo político e ao poder de grupos econômicos. Ao contrário, os proprietários de veículos de comunicação conseguiram montar uma estrutura industrial, mas extremamente dependente de verbas públicas obtidas em estabelecimentos oficiais de crédito e recursos provenientes da publicidade comercial de empresas nacionais e estrangeiras.

Com o desenvolvimento industrial do pós-guerra e a maior oferta de bens de consumo, a presença dos anunciantes tornou-se mais freqüente nas páginas dos periódicos. Para alguns autores, a presença das agências 
de publicidade, como intermediárias de grupos econômicos, nacionais e estrangeiros, representou uma ameaça à liberdade de expressão e uma tentativa de desnacionalização da imprensa.

Nesse período, registrou-se um número crescente de agências de publicidade. Enquanto na década de 1940 havia pouco mais de 50 agências no mercado, o número subiu para aproximadamente 300 no final dos anos 1950, dentre as quais podemos destacar a «J. Walter Thompson», sediada em São Paulo, e a «McCan Erickson», no Rio de Janeiro (RIBEIRO, 2000). O impulso das agências, sobretudo estrangeiras, representou conseqüentemente uma significativa expansão dos investimentos publicitários no mercado jornalístico. O volume investido em jornais e revistas, através das agências de publicidade, passou de 750 milhões em 1947 para 3,5 bilhões de cruzeiros em 1953. Desse total, cerca de 1,2 bilhões eram destinados aos jornais e 480 milhões, às revistas (SODRÉ, 1999).

No início dos anos 1950, quando a televisão ainda começava a operar no Brasil, as empresas utilizavam como principal critério para direcionar seus investimentos o fator venda (circulação), no caso dos jornais e revistas, ou audiência, no caso do rádio. As revistas ilustradas, como O Cruzeiro, pertencente ao grupo dos Diários Associados, captavam os principais anúncios. Tal procedimento utilizado pelos anunciantes agravava o processo de concentração da imprensa, pois os grandes veículos ficavam com a maior parte da divisão do bolo publicitário.

Além da atuação das agências estrangeiras de publicidade no mercado, os grandes anunciantes também eram, em sua maioria, grupos multinacionais. Dados do Anuário de Publicidade mostram as firmas que mais despendiam recursos no mercado jornalístico em 1953: Cia. Antarctica Paulista (70 milhões), Esso Standard do Brasil (28 milhões), Cia. Industrial Gessy (27 milhões), «The Sidney Ross Company» (25 milhões), S.A. Ind. Irmãos Lever (20 milhões), «The Shell Brazil Limited» (18 milhões), «The Coca-Cola Export» (15 milhões), Cia. Cerveja Brahma (14 milhões), «The Johnson \& Johnson» (13,5 milhões), «Atlantic Refining Company» (13 milhões), «Gillette Safety Razor Co.» (12,5 milhões), «The Colgate-Palmolive Pest Co.» (12 milhões), «The Eno Scott Browne \& Cia.»(12 milhões), Cia. de Cigarros Souza Cruz (12 milhões) e Companhia Nestlé (10 milhões).

A presença do capital estrangeiro na imprensa por meio da publicidade provocou intenso debate no campo jornalístico e nos meios políticos. A divisão de opiniões refletia a própria conjuntura do pós-guerra, com o acirramento da disputa entre pólos distintos. De um lado, os grupos mais liberais defendiam a abertura de mercado e viam na publicidade uma possibilidade de autonomia dos jornais em relação ao poder político. Do outro, os que assumiam um discurso nacionalista tinham uma orientação mais próxima do pensamento da esquerda. Para esses opositores, a publicidade servia como instrumento de controle dos jornais, pois interferia diretamente no noticiário.

O embate ideológico travado entre defensores e críticos da participação de empresas estrangeiras como anunciantes no mercado jornalístico reflete o contexto político daquele momento histórico. Concordamos com a idéia da concentração de mercado a partir da expansão da publicidade e dos vínculos criados, desde então, entre jornais e grupos econômicos. Longe de percebemos nesse fenômeno uma possibilidade de autonomia e independência dos jornais, como defendiam os liberais, também nos parece bastante precário o argumento, apresentado por uma corrente de pensamento carregado de uma ideologia de base marxista, de "controle estrangeiro" da imprensa nacional.

Um dos principais fatores que redimensiona o volume gasto em publicidade nos jornais pelas empresas estrangeiras - principalmente as americanas Esso Standard do Brasil e «Atlantic Refining Company» e a inglesa «Shell Brazil Limited» - envolve a questão do monopólio estatal do petróleo no país. As diferenças ideológicas em torno de debate sobre o "controle estrangeiro" da imprensa ficam ainda mais expostas. 
A situação das multinacionais petrolíferas no Brasil começou a modificar-se em 1939, quando os jornais publicaram a descoberta de petróleo nos poços de Lobato, na Bahia, região que se tornaria a primeira grande reserva nacional do produto no Brasil. Mesmo com aproveitamento comercial baixo, a extração do óleo incentivou novas pesquisas do recém-criado Conselho Nacional de Petróleo (CNP) na região do Recôncavo Baiano.

As perfurações prosseguiram em pequena escala nos anos 1940, mas era cada vez maior o consumo de derivados de petróleo. Em 1938, o consumo exigia a importação de 38 mil barris/dia. Em 1950, a demanda já era de cem mil barris. Ao mesmo tempo, crescia o apelo popular pela criação de uma empresa brasileira de produção e distribuição de petróleo. Sob a liderança do Centro de Estudos e Defesa do Petróleo, a campanha "O petróleo é nosso" foi reforçada pelo projeto nacionalista que levou Getúlio Vargas novamente ao cargo de mandatário da nação, em 1950. Em 3 de outubro de 1953, Vargas sanciona a Lei 2.004 criando a Petróleo Brasileiro S.A - Petrobras. Ficava instituído o monopólio estatal da pesquisa e lavra, exploração, refino do petróleo nacional e estrangeiro e transporte do produto e seus derivados. À Petrobras cabia a execução, ficando o CNP como órgão normativo e fiscalizador do monopólio (DHBB/FGV).

A decisão provocou forte impacto nos interesses comerciais da Esso Standard do Brasil e outras distribuidoras. A partir de 1953, as multinacionais teriam que passar a comprar os derivados de petróleo da estatal. Antes do surgimento e consolidação da Petrobras no mercado, Esso, Shell, Atlantic e outras duas multinacionais (Gulf e Texas) detinham quase a totalidade do mercado de distribuição de combustíveis no Brasil.

$\mathrm{O}$ aumento do investimento em publicidade no período representava uma reação à campanha em defesa da solução estatal do petróleo. Em 1953, ano de criação da Petrobras, a concorrente Esso exerceu papel de liderança em termos de gastos publicitários, conforme citamos anteriormente. Outras companhias de petróleo, como Shell e Atlantic, também despenderam elevados recursos com veiculação de anúncios na imprensa. Em 1956, o valor gasto em publicidade pela Esso e pela Shell, somente para a venda de combustíveis, somou 31 milhões de cruzeiros. O ritmo dos investimentos da Esso não diminuiu ao longo da década. Em 1959, os gastos da multinacional chegaram a 80 milhões de cruzeiros, aumento de $185 \%$ em relação a 1953.

O corte de verbas de uma grande companhia representava uma ameaça para a sobrevivência das empresas jornalísticas. Em discurso pronunciado na Câmara em 1953, o deputado Euzébio Rocha denunciou a Esso por tentar controlar a opinião dos jornais via publicidade. Rocha acusou diretamente a multinacional de retirar anúncios do Diário de Notícias por ter defendido, em artigos e editoriais, a nacionalização do petróleo:

Há pouco mais de um ano, a Standard Oil Company do Brasil mobilizou todos os seus recursos de propaganda e desencadeou forte campanha no sentido de obter para si a exploração das nossas reservas de petróleo. O Diário de Notícias, porque repudiasse em editoriais e em artigos de colaboradores aquelas pretensões antinacionais, foi sumariamente suprimido da programação de publicidade daquela importante empresa.(ROCHA apud SODRÉ, 1999: 434)

Na Comissão Parlamentar de Inquérito, instalada em 1957, a questão do petróleo foi apontada como determinante para o aumento da participação do capital estrangeiro na imprensa brasileira. A Esso e a agência de publicidade «McCann Erickson» foram alvo permanente de investigação. Políticos acusavam a agência de pagar publicidade apenas aos jornais contrários ao monopólio da Petrobras. Em 7 de setembro de 1962, o semanário Novos Rumos, de orientação comunista, denunciou a distribuição da publicidade da Esso, citando Emil Farhat e Armando de Morais Sarmento, dirigentes da «McCann Erickson» ouvidos pela CPI:

Naquela época, a empresa de publicidade que mantém sede em Nova Iorque, onde estão $60 \%$ de suas ações, distribuía anualmente 300 milhões de cruzeiros na propaganda de diversas firmas norte- 
americanas aqui instaladas. Sua principal cliente era a Standard Oil Company, que passou a chamar-se Esso Standard do Brasil. O atual presidente da McCann Erickson, Emil Farhat, era então assistente imediato de Armando de Morais Sarmento, que dirigia a empresa. Chamados a depor perante a Comissão Parlamentar de Inquérito, viram-se os dois personagens atrapalhados para explicar a distribuição da publicidade da Esso, dirigida apenas aos órgãos de imprensa contrários ao monopólio estatal do petróleo, suborno e corrupção que, gaguejantes e confusos, acabaram por confessar.(SODRÉ, 1999: 407)

Segundo o jornalista Genival Rabelo, a multinacional do petróleo realizou reuniões com autoridades brasileiras em 1953, ano de criação da Petrobras, fazendo advertências ao governo. Rabelo utiliza informações do Jornal de Debates, no qual o jornalista Joel Silveira descreve as ameaças da Esso: "1) que não estava de acordo com a política do monopólio estatal do petróleo; 2) que, se as autoridades insistissem na idéia, a companhia faria uma campanha de propaganda no montante de 5 milhões de dólares; 3) que, caso a campanha não surtisse efeito, deporia o governo" (SODRÉ, 1999: 434). O Jornal de Debates também mantinha uma política editorial fortemente nacionalista.

A conclusão da CPI foi publicada no Diário do Congresso Nacional em 30 de janeiro de 1959. Confirmava o poder de companhias estrangeiras no mercado de petróleo no Brasil. Os deputados observaram que, apesar de o artigo 160 da Constituição Federal proibir participação acionária de grupos estrangeiros em veículos de comunicação no país, o mesmo não ocorria com as agências de publicidade. Elas trabalhavam a serviço das multinacionais, exercendo, segundo a comissão, influência indireta no conteúdo noticioso:

Como grandes clientes, as distribuidoras exercem forçosamente notável influência sobre as agências de publicidade, levando-as também a seguir os mesmos critérios na colocação das verbas de outros clientes. Esse efeito de arrastamento canaliza a maior parcela da importância total gasta em publicidade, mais de 9 milhões de cruzeiros em 1957, para órgãos de divulgação dispostos a colaborar na defesa dos interesses dos trustes, e subtraindo a viabilidade econômica aos que persistam em posição de independência. (CONGRESSO NACIONAL, 1959: 798)

Como já mencionamos, os depoimentos e o trabalho da comissão devem ser analisados dentro do contexto de polarizações políticas. Importa lembrar que a comissão foi presidida pelo deputado Luthero Vargas, filho do ex-presidente Getúlio Vargas (5). Ressalvando a carga ideológica dos debates travados por ocasião da CPI, entendemos que alguns dados são indicativos para compreender parte das estratégias de comunicação da Esso diante das restrições comerciais impostas pelo monopólio do petróleo.

\section{O Prêmio Esso de Jornalismo}

No início da década de 1950, como vimos, as atividades da Esso no Brasil mantinham estreitas ligações com os departamentos comerciais das empresas jornalísticas. O contexto político, no entanto, era pouco favorável à manutenção de uma imagem institucional positiva. Contra a multinacional, pesavam acusações de liderar o movimento contrário à exploração ao monopólio estatal em plena campanha do "Petróleo é nosso". O grupo também era alvo de denúncias em comissões parlamentares de inquérito por tentar influenciar o noticiário por meio de (corte de) verbas publicitárias. Diante desse cenário, a empresa buscou alternativas para aproximar-se dos formadores de opinião. O objetivo era não restringir suas ações de marketing à publicidade.

Partiu do jornalista Ney Peixoto do Valle a idéia da criação de um prêmio voltado para o reconhecimento do trabalho dos profissionais das redações. Repórter político do Diário Carioca, ele deixou a imprensa em 1953 para trabalhar na companhia Esso. Para conferir credibilidade ao projeto - tendo em vista o fato de a premiação ser concedida por uma multinacional, com interesses comerciais bastante claros no país - uma das primeiras medidas de Valle foi buscar uma parceria com a Associação Brasileira de Imprensa (ABI), 
presidida por Herbert Moses.

Visando quebrar a desconfiança quanto a uma possível interferência da Esso na premiação, os idealizadores esclareciam ainda que a comissão julgadora seria formada exclusivamente por jornalistas. Percebe-se que o discurso de isenção e imparcialidade, tão presente no contexto de modernização da imprensa nos anos 1950 , também foi incorporado pela empresa como forma de garantir as condições de aceitabilidade do concurso. Nesse sentido, entendemos que a constituição do prêmio e o discurso de modernização e profissionalização do campo jornalístico caminharam juntos como instância legitimadora de certa identidade profissional do jornalista.

Com o apoio da ABI e a participação exclusiva de jornalistas na comissão julgadora, o projeto da empresa petrolífera conduzido por Ney Peixoto do Valle saiu do papel. Em 1956, foi lançada a primeira edição do Prêmio Esso de Reportagem, mais tarde rebatizado de Prêmio Esso de Jornalismo. A comissão julgadora era formada por nomes que participaram do processo de renovação dos padrões técnicos do jornalismo brasileiro. Além de Herbert Moses, presidente da ABI que avalizara a criação da premiação, o júri era composto por Alves Pinheiro (O Globo), Otto Lara Rezende (Manchete), Danton Jobim (Diário Carioca) e Antônio Callado (Correio da Manhã).

Valle afirmara que a premiação foi idealizada com o propósito de dar oportunidade aos jornalistas mostrarem seu trabalho fora do eixo Rio-São Paulo. Inspirava-se no Pulitzer, principal prêmio do jornalismo americano, mas "adaptado à realidade brasileira". Valle tinha também uma implicância com o "estrelismo" da revista O Cruzeiro (6). O resultado da primeira edição do concurso, no entanto, premiou justamente a publicação semanal do grupo dos Diários Associados. A comissão julgadora concedeu um prêmio único em 1956 para a Revista O Cruzeiro pela reportagem "Uma tragédia brasileira: os paus-de-arara", de Mário de Moraes e Ubiratan de Lemos.

Os repórteres percorreram 2,3 mil quilômetros e acompanharam durante 11 dias a viagem de 102 nordestinos em um caminhão "pau-de-arara", do interior de Pernambuco até a Baixada Fluminense, no Rio. Com fotos produzidas por Moraes e texto de Ubiratan de Lemos, a reportagem mostrou as frustrações e os sonhos dos retirantes em busca de uma vida melhor no Sul do país. Sobre a produção e a publicação da matéria na revista O Cruzeiro, em 22 de outubro de 1955, Carvalho (2001) resgata um dado interessante:

Naquele mesmo mês, outubro de 55, Amádio (José Amádio, diretor de redação de O Cruzeiro) colocou na gaveta uma matéria que Mário de Moraes e Ubiratan de Lemos suaram a camisa para fazer (...). Mário voltou com tifo e caiu de cama por três meses. Ubiratan ficou na pressão, mas nada de Amádio publicar. 'Ele tinha horror a coisa de pobre', diz Mário. No fechamento da edição de 22 de outubro de 55, faltou uma matéria paga que a sucursal de São Paulo deveria mandar. A reportagem finalmente saiu.(CARVALHO, 2001: 326)

A primeira edição do Prêmio Esso recebeu poucas inscrições. A entrega da premiação a Mario e Ubiratan também teria sido acompanhada por pouco mais de 15 pessoas durante um almoço no mezanino da Mesbla, no Rio de Janeiro. Essas informações constam na edição comemorativa dos 50 anos do concurso (2006). O número reduzido de participantes demonstrava o desinteresse inicial e o descrédito de grande parte dos jornalistas em relação ao concurso criado por Ney Peixoto do Valle. Como relata o próprio Valle, da diretoria da empresa só estava presente o gerente geral de Vendas, Walter Hostmann.

O prestígio alcançado pelo Prêmio Esso de Reportagem começaria a ser construído nos anos seguintes, concomitantemente ao processo de profissionalização da imprensa. Logo em seu segundo ano, algumas mudanças foram feitas no regulamento: os organizadores deixaram de conceder uma premiação única, incorporando, além da principal, duas categorias regionais, uma para a Região Norte-Nordeste e outra para a 
Região Sul. Em 1959, foi criado um terceiro prêmio regional, destacando o melhor trabalho na região central do país. As mudanças contemplavam o objetivo inicial de Valle de reconhecer a produção jornalística em outras cidades, para além do eixo Rio-São Paulo.

Com a valorização do fotojornalismo na imprensa brasileira, foi criada em 1961 a categoria fotografia. Nessa época, a comissão julgadora também já concedia destaques especiais, votos de louvor e menções honrosas, e o programa batizado inicialmente de Prêmio Esso de Reportagem passou a ser denominado Prêmio Esso de Jornalismo. As alterações no regulamento coincidiam com as mudanças verificadas na própria imprensa brasileira. Com a especialização das editorias ainda nos anos 1960, outras categorias foram implantadas, como o melhor trabalho esportivo, a melhor reportagem econômica e o prêmio de informação científica, além da concessão do Prêmio Esso de Equipe e de Melhor Contribuição à Imprensa.

Atualmente, além do Prêmio Esso de Jornalismo, são distribuídos prêmios em 11 categorias, incluindo Criação Gráfica e Primeira Página. A televisão também passou a fazer parte do concurso, desde 2001, com a entrega do Prêmio Esso de Telejornalismo. Segundo o regulamento, só podem concorrer "trabalhos escritos em língua portuguesa, de autoria de profissionais brasileiros, e publicados em revista e jornal brasileiros, com sede no país" (item 2.5 do regulamento de 2007).

Em 52 anos de premiação (1956-2008), concorreram mais de 20 mil trabalhos jornalísticos, segundo a companhia. O grande número de inscritos levou os organizadores a instituir, em 1994, um sistema de julgamento em duas instâncias. Uma comissão de seleção indica três trabalhos finalistas em cada categoria, que são avaliados, numa segunda etapa, por uma comissão de premiação, responsável pelo resultado final do concurso. A exceção é a categoria de fotografia, na qual são indicados pela comissão de seleção os cinco melhores trabalhos. Uma comissão especial - formada por 50 jornalistas e editores de fotografia - tem como atribuição escolher o vencedor nesta categoria. As mudanças refletem um cenário completamente distinto em relação aos primeiros anos, quando havia uma única comissão, composta por apenas cinco membros.

\section{Bibliografia:}

ARONCHI DE SOUZA, José Carlos. Gêneros e formatos na televisão brasileira. São Paulo: Summus, 2004. BAHIA, Juarez. Jornal, História e Técnica: história da imprensa brasileira. São Paulo: Ática, 1989.

BELOCH, Israel e FAGUNDES, Laura Reis (org.). Uma história escrita por vencedores: 50 anos do Prêmio Esso de Jornalismo. Rio de Janeiro: Memória Brasil, 2006.

CARVALHO, Luiz Maklouf. Cobras criadas: David Nasser e O Cruzeiro. São Paulo: Senac, 2001.

CASSOL, Ivone Maria. Prêmio Esso e as transformações da reportagem: uma reflexão sobre a reportagem e o jornalismo impresso nos últimos 40 anos na Região Sul. Porto Alegre: PUC-RS, 1997 (dissertação de mestrado).

CURADO, Olga. A notícia na TV: o dia-a-dia de quem faz telejornalismo. São Paulo: Alegro, 2002.

JUNG, Milton. Jornalismo de rádio. São Paulo: Contexto, 2005.

KLÖCKNER, Luciano. "O repórter Esso e a globalização: a produção de sentido no primeiro noticiário radiofônico mundial”. In: XXIV Congresso Brasileiro de Comunicação (Intercom), Campo Grande/MS, 2001. MORAIS, Fernando. Chatô, o rei do Brasil. São Paulo: Companhia das Letras, 1994.

MOREIRA, Sonia Virginia. O rádio no Brasil. Rio de Janeiro: Rio Fundo, 1991.

PATERNOSTRO, Vera Íris. O texto na TV: manual de telejornalismo. Rio de Janeiro: Elsevier, 1999.

RIBEIRO, Ana Paula Goulart. Imprensa e história no Rio de Janeiro dos anos 50. Rio de Janeiro: UFRJ, 2000 (tese de doutorado).

SILVA, Carlos Eduardo Lins da. O adiantado da hora: a influência americana sobre o jornalismo brasileiro. São Paulo: Summus, 1991.

SODRÉ, Nelson Werneck. A História da Imprensa no Brasil. Rio de Janeiro: Civilização Brasileira, 1966. 


\section{Notas:}

Trabalho selecionado para o GT História do Jornalismo do VI Congresso Nacional de História da Mídia (Rede Alçar, 2008).

(1) A Rádio Record, de São Paulo, foi criada em 1931 num cenário de institucionalização da publicidade comercial. Pelo decreto do governo provisório de Getúlio Vargas, apenas $10 \%$ da programação podiam ser ocupados por anúncios. A Rádio Nacional, com sede na Capital da República, possuía uma das maiores estruturas radiofônicas do país. Em 1940, um ano antes da estréia do Repórter Esso, a rádio fora encampada pelo governo Vargas, no período do Estado Novo (JUNG, 2005: 31).

(2) Para implantar a televisão no Brasil, Chateaubriand importou os equipamentos e decidiu trazer técnicos americanos da RCA. Em 18 de setembro de 1950, entrava no ar a PRF-3 TV Difusora, depois TV Tupi de São Paulo, primeira emissora de TV da América Latina. O dono dos Diários Associados mandou instalar 200 aparelhos em pontos movimentados da capital paulista para o público comprovar a existência da televisão.

(3) O plano americano ou médio é um enquadramento que se tornou padrão para filmar a participação de repórteres nas matérias. A tomada é feita da cintura para cima se a pessoa estiver de pé (Curado, 2002: 108).

(4) No período de 1958 a 1963, a alta do preço do papel importado para a imprensa foi superior a 3.294\%. O período também apresentava sucessivos aumentos do preço do dólar para a importação. A ascensão do preço do papel nacional acompanhava a do papel estrangeiro. O dólar para importação de papel passou de Cr\$18,82 em 1958 para Cr\$ 620 em 1963. No mesmo período, o quilo de papel nacional passava de Cr\$4,63 para Cr\$ 112 (SODRÉ, 1999).

(5) Integravam também a CPI os deputados Dagoberto Salles (relator), José Joffilly, Gabriel Passos, José Miraglia e Adolfo Gentil.

(6) Jornal das Faculdades Integradas Hélio Alonso, novembro de 2005. Disponível em: www.facha.edu.br/publicacoes/jornallab_meier/2005/novembro/pag6e15.pdf

\section{Mini Currículo :}

Mestre em Comunicação, Imagem e Informação pela Universidade Federal Fluminense (UFF) e doutorando em Comunicação e Cultura pela Universidade Federal do Rio de Janeiro (UFRJ). E-mail: castilhorio@terra.com.br.Trabalho selecionado para o GT História do Jornalismo do VI Congresso Nacional de História da Mídia (Rede Alçar, 2008). 